\title{
Investigating Prediction Performance of an Artificial Neural Network and a Numerical Model of the Tidal Signal at Puerto Belgrano, Bahia Blanca Estuary (Argentina)
}

\author{
Jorge O. PIERINI ${ }^{1}$, Michele LOVALLO ${ }^{2}$, Luciano TELESCA ${ }^{3}$, \\ and Eduardo A. GÓMEZ ${ }^{4}$
}

${ }^{1}$ Comisión de Investigaciones Científicas, Universidad Nacional del SurConsejo Nacional de Investigaciones Científicas y Técnicas, Bahía Blanca, Argentina

${ }^{2}$ Agenzia Regionale per la Protezione dell'Ambiente (ARPAB), Potenza, Italy

${ }^{3}$ National Research Council, Institute of Methodologies for Environmental Analysis,

Tito, Italy; e-mail: luciano.telesca@imaa.cnr.it (corresponding author)

${ }^{4}$ Centro Cientifico Tecnologico, Universidad Nacional del SurConsejo Nacional de Investigaciones Científicas y Técnicas,

Bahía Blanca, Argentina

\section{Abstract}

In the present study we compare performances of the prediction of hourly tidal level variations at Puerto Belgrano, a coastal site in the Bahia Blanca Estuary (Argentina), by means of the MOHID model, which is a numerical model designed for coastal and estuarine shallow water applications, and of an artificial neural network (ANN). It was shown that the ANN model is able to predict the hourly tidal levels over long term duration with at least seven days of observations and with a better performance in respect to the numerical model. Our findings can be useful to implement ANN-based tools for future studies of the hydrodynamics of Bahía Blanca estuary.

Key words: artificial neural networks, hydrodinamic model, tides. 


\section{INTRODUCTION}

Predicting accurately the sea water level is important in a large variety of coastal and open ocean activities (e.g., commercial transportation, coastal and offshore constructions); therefore it is a challenging task in the context of monitoring complex marine ecosystems and oceanographic research.

Sea water level is intrinsically nonstationary, because it depends on several variables, like tides, temperature, salinity, atmospheric forcing and ocean current; furthermore, it also depends on shoreline and bathymetry. Therefore, the physical process underlying sea level variability is extremely complex and not fully understood yet (Lovallo et al. 2012). The process becomes more complex in the nearshore area due to the bathymetry and coastal geomorphology.

Generally, the sea water level is observed at some coastal tide-gauge stations; in fact, due to high cost of field data measurements, water level observations are available only for a limited number of sites in a certain region for a quite long period of observation.

The variability of water level can be studied by a hydrodynamic numerical model, whose accuracy depends on the accuracy of knowledge of forcing fields, parameters and boundary conditions. But generally speaking a hydrodynamic numerical model is characterized by a great number of prognostic and diagnostic variables, since it resolves a 2D or 3D high resolution field, thus requiring an enormous computational effort.

The hydrodynamic numerical model called MOHID (Martins et al. 2001, Leitão 2003) is a barotropic finite volume model, just designed for coastal and estuarine shallow water applications, allowing an integrated modelling approach of physical and biogeochemical processes.

Recently, artificial neural networks (ANNs) have been widely applied in various fields to overcome the problem of nonlinear relationship among physical systems and predicting some phenomena in marine environment (Williams 1994, Grubert 1995, Mase 1995, Mase et al. 1995). Vaziri (1997) used ANN models for predicting Caspian Sea mean monthly surface water level. Deo and Chaudhari (1998) used ANN which was trained using three algorithms, namely error back-propagation, cascade correlation and conjugate gradient for predicting tides. Tsai and Lee (1999) examined the applicability of the back-propagation neural network (BPN) to forecast the hourly tidal variation.

ANNs are able to predict a complex system's behavior without any prior knowledge of the internal relationships among its components, by recognizing the hidden pattern in the data on the basis of a reasonably large amount of data. The stochastic nature of the water level variability makes the ANN modelling an ideal choice because it is mainly focused on the identification 
of a random pattern in a certain set of observed data without a thorough understanding of the underlying physical process as a prerequisite.

The performances of the ANN and the MOHID model were measured by using the relative root mean squared error (RMSE), the skill index (SKI, Willmott 1982) and correlation coefficient, $R$. They are defined by

$$
\begin{gathered}
\mathrm{RMSE}=\sqrt{\frac{\sum_{i=1}^{N}\left(y_{i}-x_{i}\right)^{2}}{\sum_{i=1}^{N} x_{i}^{2}},} \\
\mathrm{SKI}=1-\frac{\sum_{i=1}^{N}\left(y_{i}-x_{i}\right)^{2}}{\sum_{i=1}^{N}\left(\left|y_{i}-\bar{x}\right|+\left|x_{i}-\bar{x}\right|\right)^{2}}, \quad 0 \leq \mathrm{SKI} \leq 1, \\
R=\frac{\sum_{i=1}^{N}\left(x_{i}-\bar{x}\right)\left(y_{i}-\bar{y}\right)}{\sqrt{\sum_{i=1}^{N}\left(x_{i}-\bar{x}\right)^{2} \sum_{i=1}^{N}\left(y_{i}-\bar{y}\right)^{2}}},
\end{gathered}
$$

in which $y_{i}$ is the value of prediction, $x_{i}$ denotes the value of the observation, $N$ is the total number of data, $\bar{y}$ is the mean of prediction, and $\bar{x}$ is the mean value of observation.

\section{STUDY AREA}

The Bahía Blanca estuary is shown in Fig. 1. The Principal Channel is located in the middle of the mesotidal and shallow estuary situated in the southeast of the Buenos Aires province, in Argentina. The study area from the mouth of the estuary to the head is approximately $79 \mathrm{~km}$ long, has an averaged width of about $200 \mathrm{~m}$ and a mean depth, along its longitudinal axis, of about $10 \mathrm{~m}$. The tides are semidiurnal, being M2 the most important constituent, representing more than $90 \%$ of the tidal energy (Pierini 2007). The es- timated tidal prism of the estuary head at extreme spring and extreme neap is $6.5 \times 10^{9}$ and $1.0 \times 10^{10} \mathrm{~m}^{3}$, respectively, with an average value of $8.4 \times 10^{9} \mathrm{~m}^{3}$. The total estimated freshwater input of the estuary is very small (about $4.4 \times 10^{4} \mathrm{~m}^{3}$ during a complete tidal cycle) when compared to the tidal prism at both the mouth and the head of the Principal Channel. Although the rivers discharge small amount of water, when compared to the tidal prism, they may have a long-term influence in the residual transport. Previous studies by Pierini et al. (2008a) and Pierini (2007) revealed that the tide is strongly distorted as it progresses upstream from the mouth towards the end of the channels of the estuary, due to changes in channel's geometry and 


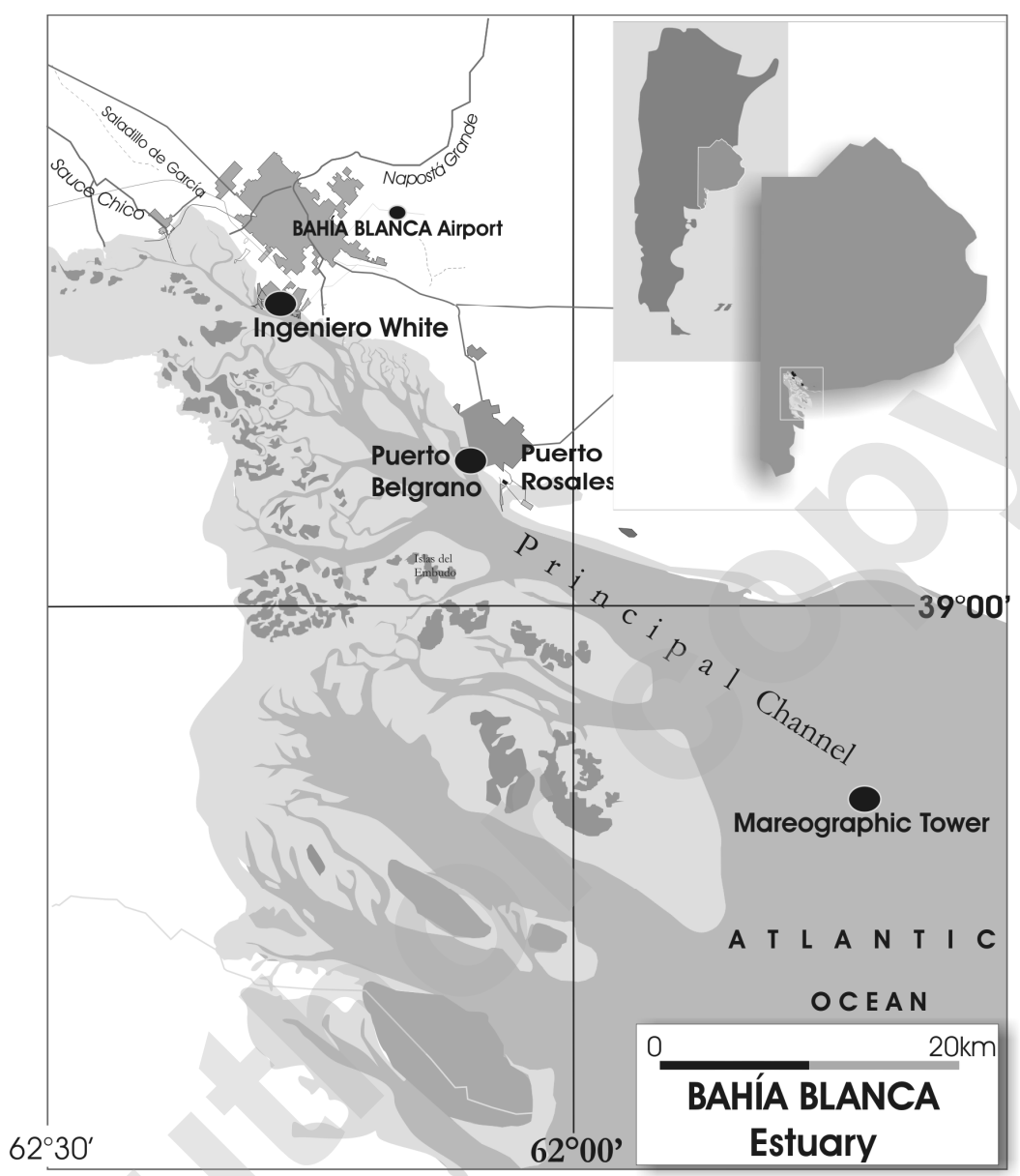

Fig. 1. Bathymetry, Puerto Belgrano tidal gauge location and discharges within the estuary.

bathymetry. The general characteristics of the tidal wave are those of a damped progresssive wave. Nevertheless, in shallow areas the tidal wave assumes the main characteristics of a standing wave. From a dynamical point of view, the Principal Channel may be considered the most important area of the estuary, because the strongest currents are observed here, reaching values higher than $2 \mathrm{~ms}^{-1}$. The other channels are shallow and tidal areas are flat, contributing to a strong damping of currents.

Tide enters each bay of the Bahía Blanca estuarine system by its southern margin at practically the same time. When the tidal wave enters, it finds all the channels reduced in width and most of the intertidal areas emerged. As the tide advances, water starts to cover the intertidal area amplifying the 
submerged area. As a result of the interaction of the tidal wave with the shallow depths of the channels, the overtides importance increases. Maximum tidal amplitudes are thus found at the innermost areas for each of the three different channels. Absolute maximum water levels were found at the innermost area of the Principal Channel. During high tides, the connections between the different bays reach their maximum width favouring water exchange between bays. When the tidal wave retreats, water scours from the inundated intertidal areas through tidal channels into the main channels, the time to evacuate those waters is long and so this process is taking place when a new tidal wave is entering.

\section{DATA}

We analyse the hourly sea level data at station Puerto Belgrano $\left(38^{\circ} 53^{\prime} 45.17^{\prime \prime} \mathrm{S}, 6^{\circ} 6^{\prime} 4.79^{\prime \prime} \mathrm{W}\right.$ ), obtained from CGPBB (Consorcio de Gestión del Puerto de Bahía Blanca) (Fig. 1). The reference level for the tide gauge is set to zero. The period from January to December 2003 was considered in the present study (Fig. 2).

Bathymetric data used for composing the model bathymetry come mainly from two sources: the GEBCO digital atlas, a one minute global bathymetric grid database (IOC et al. 2003) and from CGPBB with a waterline obtained from evaluation of 6 sets of Landsat 5 TM y Landsat 7 ETM data resulting in a high density bathymetry $\left(0.002^{\circ}\right)$ for the tertiary domain (Pierini 2007).

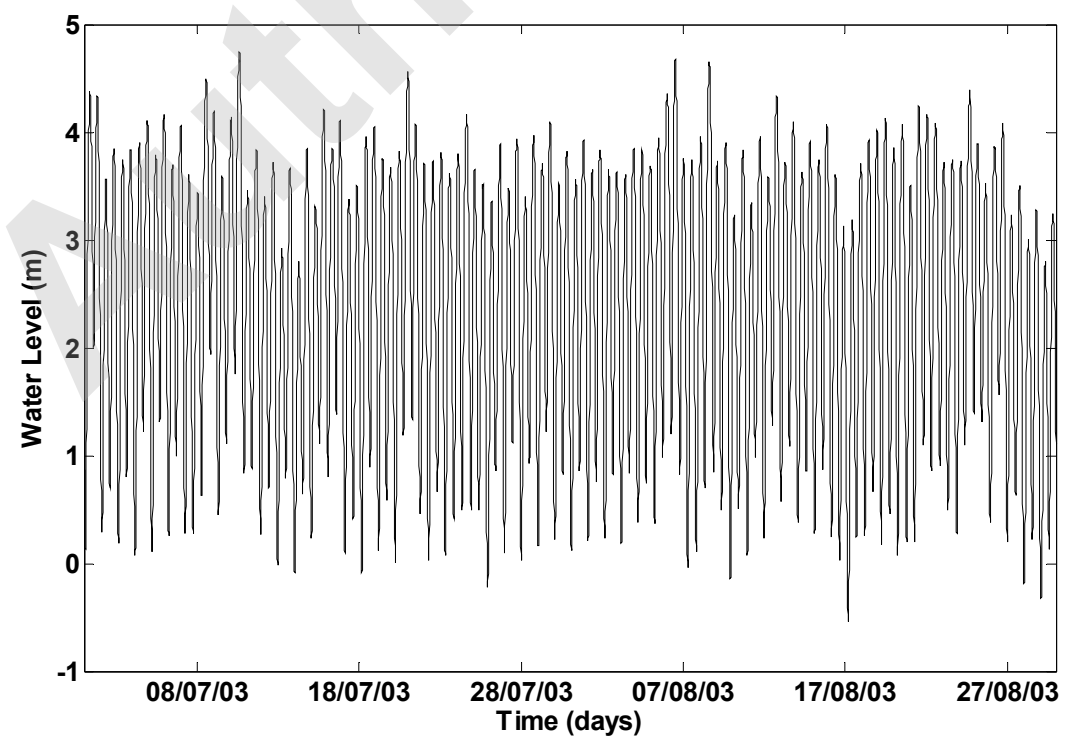

Fig. 2. Water level data measured at Puerto Belgrano tidal gauge. 
Climatological radiation levels were calculated by the model for the geographical coordinates of the domain. Cloud cover was also used to force the model, with monthly values taken from field observations made at Bahía Blanca meteorological station (Airport 38 $8^{\circ} 3^{\prime} 58.72^{\prime \prime} \mathrm{S}, 6^{\circ} 9^{\prime} 31.97^{\prime \prime} \mathrm{W}$ ) (Fig. 1) during 1990-2000 decade. Relative humidity, air temperature, and wind were also used to force the model, with hourly values taken from field observations made at Puerto Rosales meteorological station $\left(62^{\circ} 04^{\prime} 00^{\prime \prime} \mathrm{W}\right.$ $38^{\circ} 53^{\prime} 00^{\prime \prime} \mathrm{S}$ ) (Fig. 1) during study period. Time series representations are not shown for brevity. Wind forcing plays an important role on estuary dynamics and water level in Bahía Blanca estuary. Wind conditions can modify tidal levels on Bahía Blanca, being the effect more intense when wind blows along the main channel axis.

The boundary conditions considered for open Atlantic boundaries and the initial conditions for the model are temperature $\left(19^{\circ} \mathrm{C}\right)$ and salinity (35 psu). There are other creeks flowing into the Bahía Blanca Estuary, as Saladillo de García creek $\left(0.01 \mathrm{~m}^{3} \mathrm{~s}^{-1}\right)$ with an overall flow lower than the Napostá Creek itself (Pierini 2007) (Fig. 1). Official data obtained, made available by ABSA (Aguas Bonaerenses S.A.), estimates a discharge of $0.58 \mathrm{~m}^{3} \mathrm{~s}^{-1}$ on average (Pierini et al. 2012). All discharges are characterized by a salinity of 0.5 and temperature of $19^{\circ} \mathrm{C}$.

\section{THE ARTIFICIAL NEURAL NETWORK}

The ANN is an information-processing system mimicking the biological neural network of the brain. Since the principle of ANN has been well documented in the literature, only a brief explanation is given in this section. The feasibility of three-layer for the reproduction of complex system behaviour was proved empirically by a number of applications (Huang et al. 2003, Lee 2004, Makarynskyy et al. 2004, Pierini and Gómez 2009).

Such ANN, with an input layer, $I$, a hidden layer, $H$, and an output layer, $O$ (Fig. 3), is adopted in this study. Each layer consists of neurons and the layers are interconnected by sets of correlation weights, which enable the network to process the data. Nodes in input layer receive the measured data values for learning the network and pass them on to the hidden layer, as shown in Fig. 3. The neurons receive inputs from the initial data or the interconnections and produce outputs by transformation using an adequate nonlinear transfer function. A common transfer function is the sigmoid function expressed by $f(x)=\left(1+e^{-x}\right)^{-1}$; it has characteristics of $\mathrm{d} f / \mathrm{d} x=f(x)[1-f(x)]$. The training process of neural network is essentially executed through a series patterns. In the learning process, the interconnection weights are adjusted within input and output value. The Back-Propagation Network (BPN) is the most representative learning model for the ANN. In back-propagation 


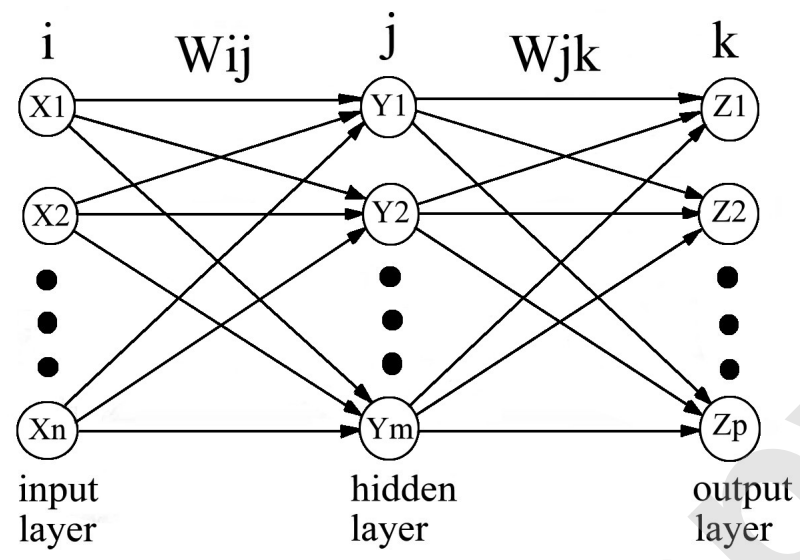

Fig. 3. Structure of an artificial neural network.

networks, the weights of the connections are adjusted to minimize the measure of the difference between the actual output vector of the network and the desired output vector. This paper applied the BPN technique with quickprop process to predict the hourly tidal variations (Fahlman 1988). This output is then compared to the target data, from which the network error is determined. Error is then back propagated through the network in order to adjust the weights and biases associated with each neuron in the network layers. The gradient descent method is utilized to calculate the weight of the network and adjust the weight of interconnections to minimize the output error. The error function at the output neuron is defined as

$$
E=\frac{1}{2} \sum_{k}\left(T_{k}-O_{k}\right)^{2},
$$

where $T_{k}$ and $O_{k}$ are, respectively, the value of target and output. Further details of the BPN algorithm can be found in Rumelhart et al. (1986).

The record of the Puerto Belgrano tide gauge was divided in two data sets; one of them served to train the ANN, and the other was used to validate the retrieval procedure. The performance of the neural network depends on the number of hidden layers and the number of neurons in the hidden layer. Table 1 shows the root mean squared error (RMSE) with zero, one, two and three hidden layers. The results show one hidden layer has the best performance. Table 2 shows the RMSE for different number of neurons, and suggests that the performance of the BPN is best with 5 neurons.

The value of the learning rate, $\eta$, significantly affects the convergence of the neural network learning algorithm, and the momentum factor, $\alpha$, is used to avoid stopping the learning process at a local minimum instead of global 


\section{Table 1}

Results with different hidden layers

\begin{tabular}{|c|c|c|}
\hline Location & Hidden layers & RMSE \\
\hline Puerto Belgrano & 0 & 0.0838 \\
& 1 & 0.0825 \\
& 2 & 0.0841 \\
& 3 & 0.0852 \\
\hline
\end{tabular}

Table 2

Results with different hidden neurons

\begin{tabular}{|c|c|c|}
\hline Location & $\begin{array}{c}\text { Neurons of } \\
\text { hidden layers }\end{array}$ & RMSE \\
\hline Puerto Belgrano & 1 & 0.0841 \\
& 3 & 0.0834 \\
& 5 & 0.0825 \\
& 7 & 0.0830 \\
& 9 & 0.0838 \\
\hline
\end{tabular}

minimum (Jacobs 1988). Either low $\eta$ or high $\alpha$ is expected to accelerate the convergence of the training process. After some preliminary tests, we used a learning rate of 0.05 , a momentum factor of 0.75 , and the number of training iterations being 1500 in all cases examined.

\section{THE MOHID MODEL}

The MOHID model has been configured to be implemented in the Bahía Blanca estuary, whose bathymetry was obtained by the CGPBB data. More recent bathymetric data, obtained from recent dredging operations in several channels and remote sensor images, were also used (Pierini 2007). Bathymetry is probably the most important among the factors affecting the flow properties in shallow systems like Bahía Blanca estuary, because it controls the spatial variability of current magnitude and direction, and is necessary for the reliability of the numerical model. Thus, the more accurate the bathy- metric representation of the estuary, the more successful the modelling. Furthermore, a compromise between a sufficiently fine model grid, to resolve the essential features of the depth and the geometry variations, and the computational time, which increases geometrically with the size of the grid, should be found. In our case we chose the cell dimension of $50 \mathrm{~m}$, producing a grid of size $(340,580)$ in directions (eastward, northward). The domain was designed to resolve the estuary's dynamics and 
not the dynamics of the near coastal ocean. Bahía Blanca estuary is an estuary where the tidal prism spreads toward the main channels and extensive tidal flats. This induces a decrease of the tidal prism through the channel affecting the dynamics of all the study area. The Sauce Chico River and Napostá Creek (Fig. 1) were included in the grid in order to simulate the inflow/outflow of water between the Principal Channel and the neighbourhood channels. Thus, in order to simulate this inflow/outflow, the model uses as boundary conditions water flow, salinity and water temperature time series computed using a 2D (depth-integrated) application of the model for all the study area. At the oceanic and landward boundaries, the water temperature and salinity are considered fixed in each simulation. At the surface, heat flux was imposed. The model uses the heat flux parameterizations described by Chapra (1997). The time step is $60 \mathrm{~s}$ and the horizontal eddy viscosity is $50 \mathrm{~m}^{2} \mathrm{~s}^{-1}$. The initial conditions for the hydrodynamic model are null free surface gradient and null velocity in all grid points. For the transport model, the initial conditions are salinity and water temperature fields, obtained by interpolation of data collected in the study area. A value of $50 \mathrm{~m}^{2} \mathrm{~s}^{-1}$ was considered for both salt and heat diffusion coefficients. The 2D application is fully described in Pierini et al. (2008a, b, c) and Campuzano et al. (2008).

\section{RESULTS}

According to past records, the highest water level in Puerto Belgrano is $5.86 \mathrm{~m}$, the lowest one is $-0.61 \mathrm{~m}$ and the average tidal range is $2.49 \mathrm{~m}$. In addition, it is a semidiurnal tide with regular rise and fall twice per day (Pierini 2007). The RMSE, R, and SKI were used to evaluate the accuracy of the ANN and the MOHID models.

Figures 4 to 6 show the BPN prediction of the tidal level at Puerto Belgrano in thirty days using a training set of seven days $(d=7)$, fifteen days $(d=15)$, and thirty days $(d=30)$ since 24 June, 15 June, and 1 June 2003, respectively. The predicted data agree quite well with the measured data. The prediction of tidal level with a training duration of thirty days is better than that with seven day. The values of the correlation coefficient $R$ are $0.961,0.986$, and 0.994 , respectively, for seven, fifteen, and thirty days (Table 3), suggesting a good agreement between observations and predictions by using the ANN with short-term tidal data (seven day).

Figures 7 to 9 show the prediction of the tidal level at Puerto Belgrano in thirty days based on the MOHID model; Table 4 shows the RMSE, R, and SKI values for the MOHID model in the same conditions as the ANN. The RMSE is 0.283 to 7 days, however the errors decrease to 0.124 when we use 30 days. This indicates that longer runs of the model can improve the ac- 

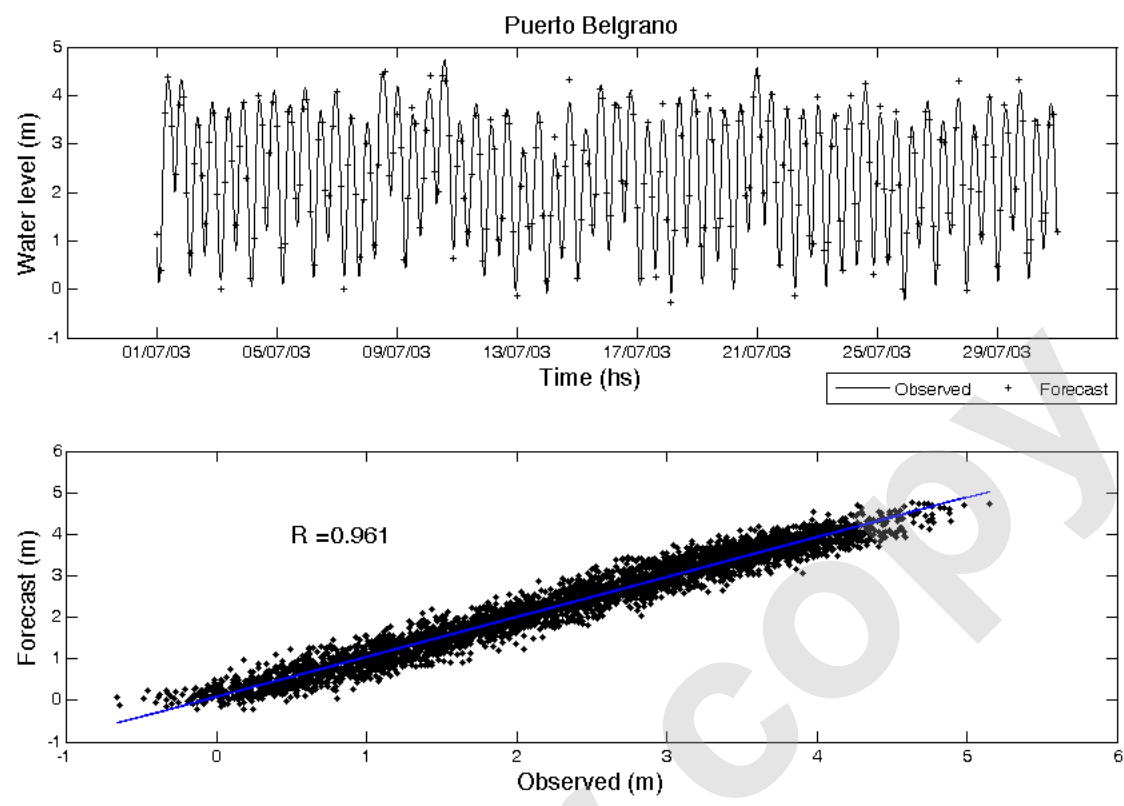

Fig. 4. BPN prediction of the tidal level at Puerto Belgrano in thirty days using a training set of seven days $(d=7)$ since 24 June 2003 .
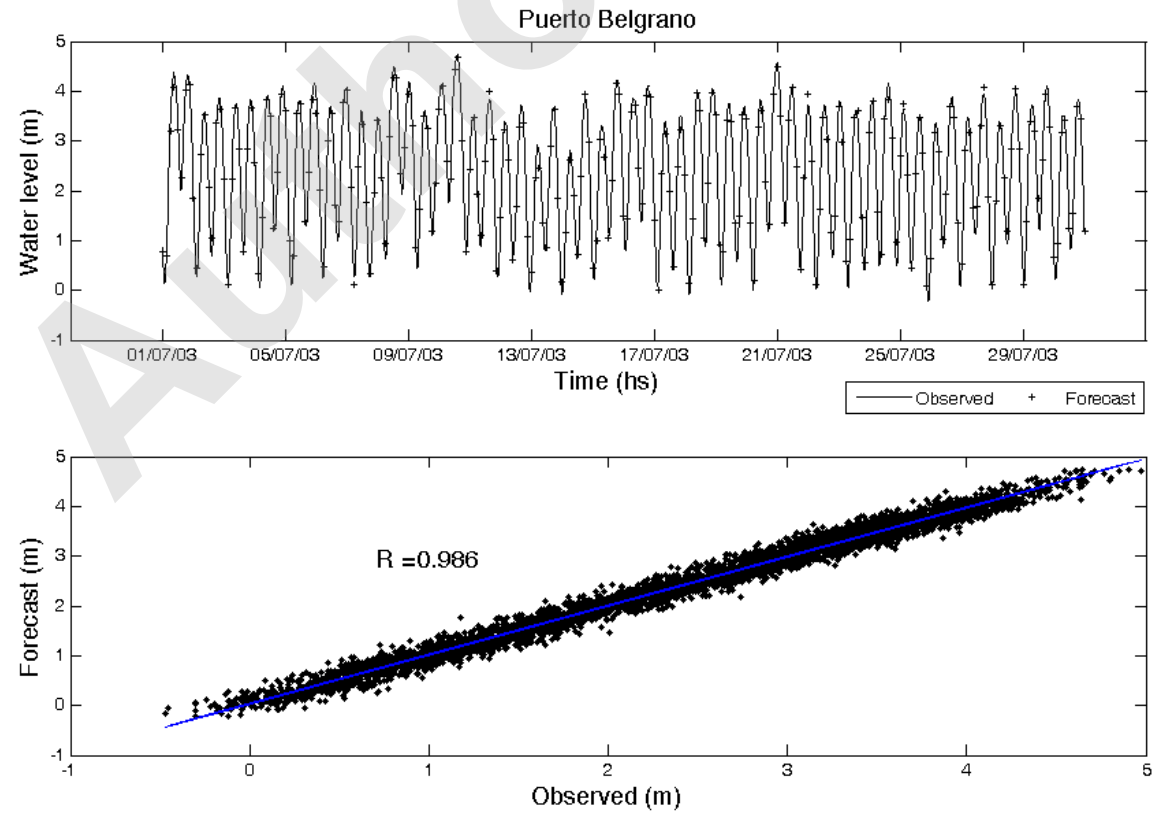

Fig. 5. BPN prediction of the tidal level at Puerto Belgrano in thirty days using a training set of fifteen days $(d=15)$ since 15 June 2003. 

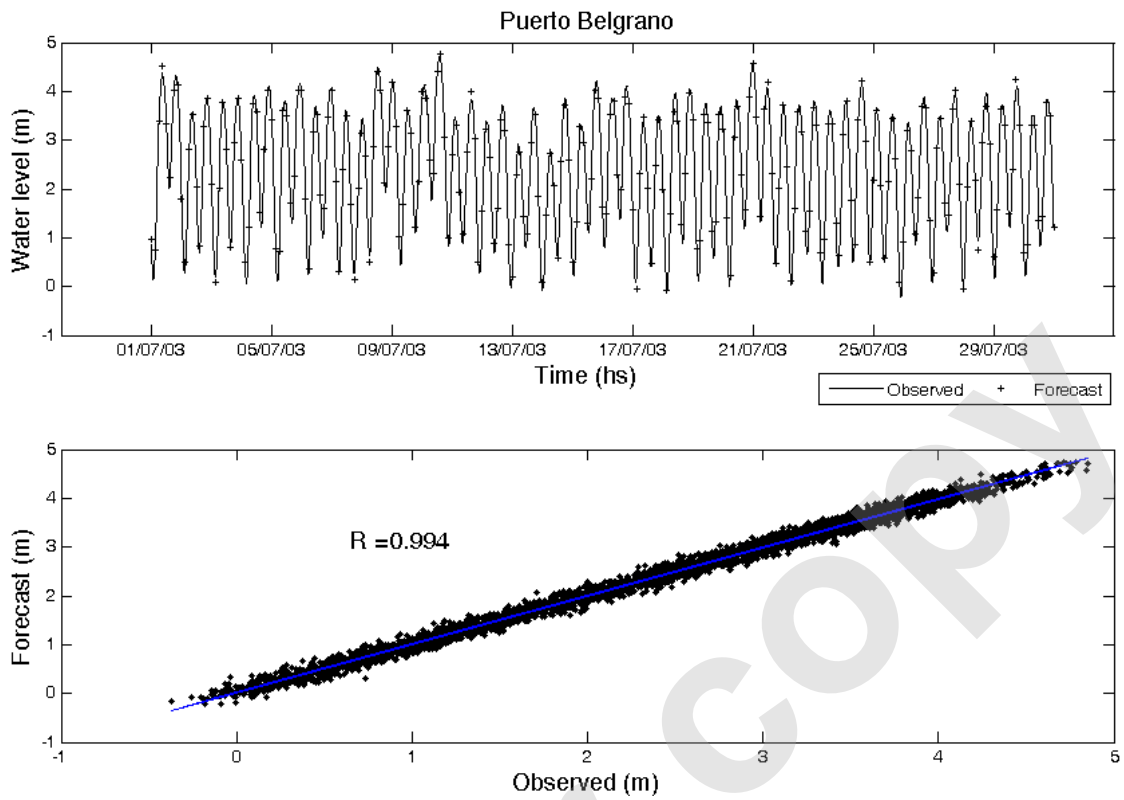

Fig. 6. BPN prediction of the tidal level at Puerto Belgrano in thirty days using a training set of thirty days $(d=30)$ since 1 June 2003 .
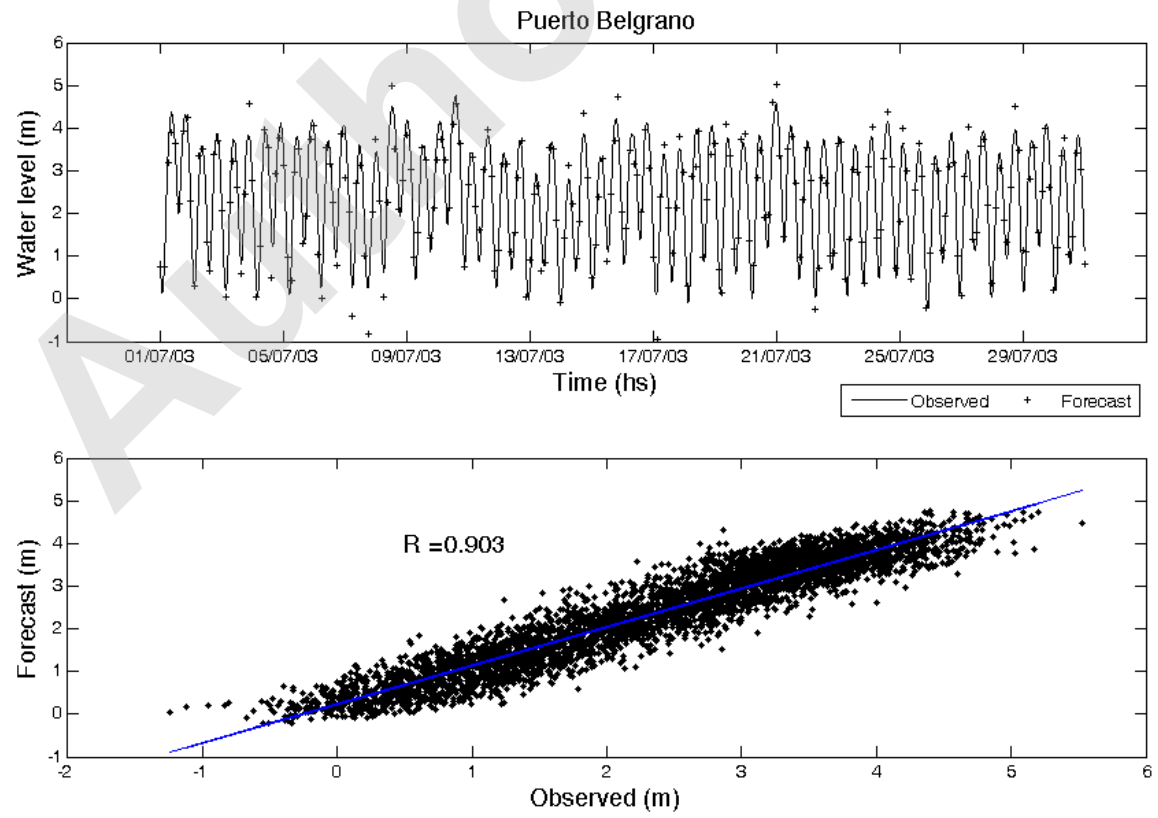

Fig. 7. MOHID prediction of the tidal level at Puerto Belgrano in thirty days using a training set of seven days $(d=7)$ since 24 June 2003 . 

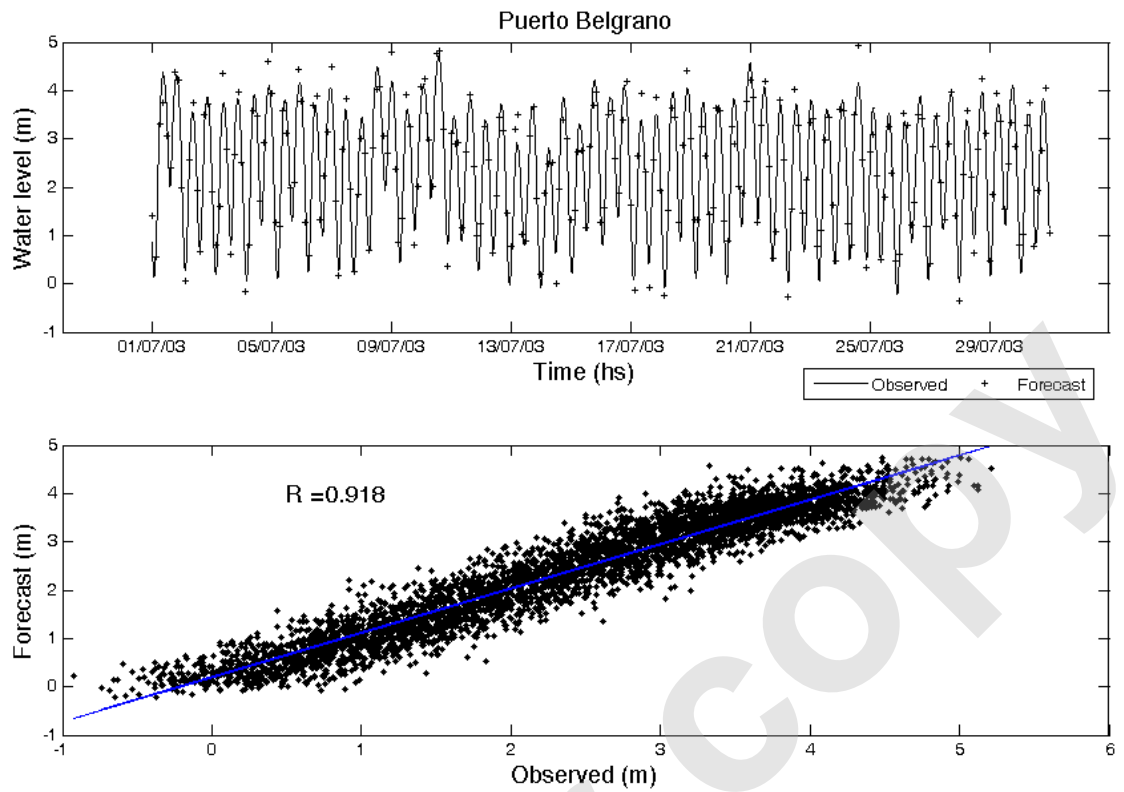

Fig. 8. MOHID prediction of the tidal level at Puerto Belgrano in thirty days using a training set of fifteen days $(d=15)$ since 15 June 2003 .
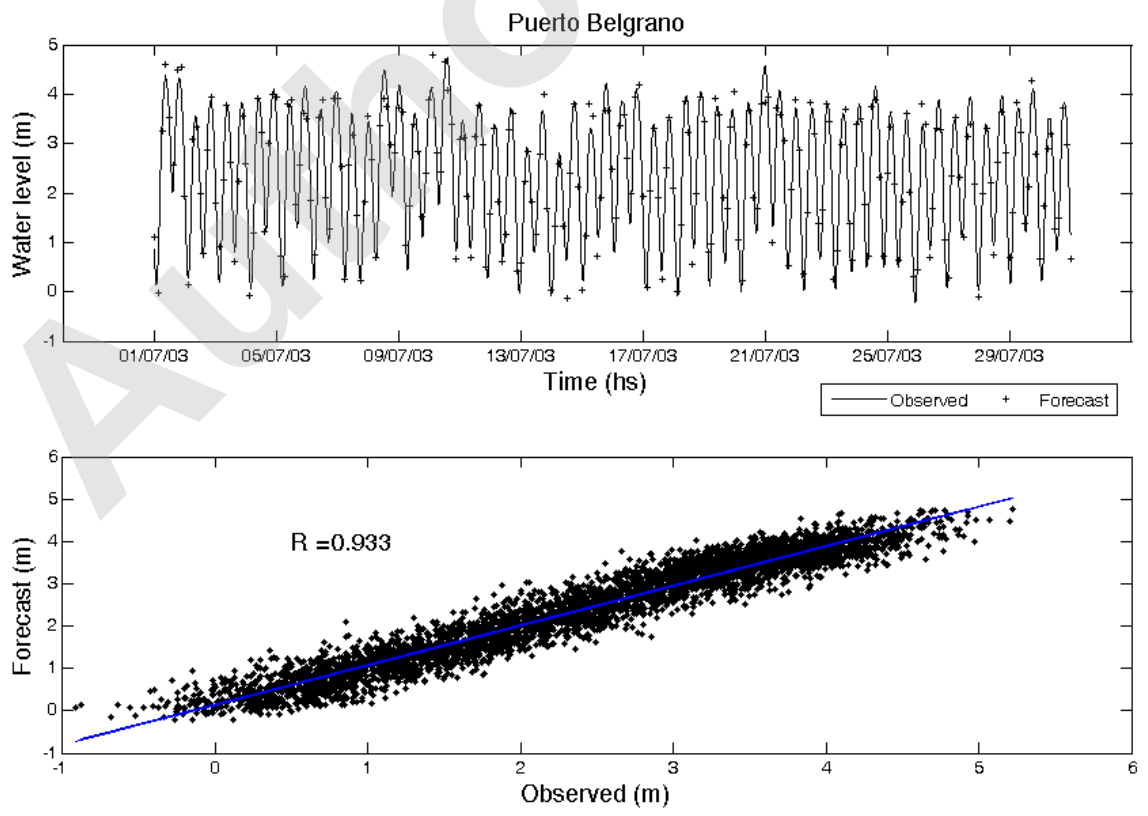

Fig. 9. MOHID prediction of the tidal level at Puerto Belgrano in thirty days using a training set of thirty days $(d=30)$ since 1 June 2003 . 
Performance over one year using measurements over different days BPN since 1 July 2003

\begin{tabular}{|c|c|c|c|}
\hline Training sets & RMSE & SKI & R \\
\hline 7 days - since 23 June 2003 & 0.178 & 0.977 & 0.961 \\
15 days - since 15 June 2003 & 0.082 & 0.992 & 0.986 \\
30 days - since 1 June 2003 & 0.047 & 0.997 & 0.994 \\
\hline
\end{tabular}

Table 4

Performance over one month using measurements over different heat days MOHID numerical model since 1 July 2003

\begin{tabular}{|r|c|c|c|}
\hline Time Heat MOHID to 1/7/03 & RMSE & SKI & R \\
\hline 7 days - since 23 June 2003 & 0.283 & 0.916 & 0.903 \\
15 days - since 15 June 2003 & 0.198 & 0.927 & 0.918 \\
30 days - since 1 June 2003 & 0.124 & 0.938 & 0.933 \\
\hline
\end{tabular}

curacy of prediction at Puerto Belgrano, due to the inclusion of some oceanographic processes that take place in a longer time.

The major shortcoming of the MOHID model is the large amount of spatial data required for a good calibration and validation over the study area (winds, sea levels, and currents data); while the major advantage of the ANN model is to predict a long-term tidal level with short-term collected data. Our findings also indicate that the BPN is capable of learning the level variations to predict the level variation using only very short-term observations. In other words, to reach reasonable accuracy of the prediction for a long term forecasting at least 15 day training data are required. From the results, comparing the correlation coefficient of the BPN $(R=0.994)$ with that of the MOHID $(R=0.933)$, it is found that the BPN is more accurate. Comparing also the other statistical performance parameters, the ANN model resulted better than the MOHID model. The scatter plots of the BPN model and the MOHID model further illustrate the different performance (Figs. 4-9). In particular, the BPN model ranges from 0.178 to $0.047 \mathrm{~m}$, whereas the MOHID model produces values ranging from 0.283 to $0.124 \mathrm{~m}$.

Regarding the performance of the BPN, the size of the data set can likely affect the reliable modelling of the transfer function. A relatively small size of the data set primarily affects the BPN results by limiting the model complexity and reducing the effectiveness of cross validation. These two effects are not independent. The size of the data set limits the number of free variables (weights and biases) in BPN models, effectively controlling the extent 
to which a BPN structure can grow. Thus, complex relationships that might require a large number of neurons and additional hidden layers in order to achieve very accurate results are stunted and not able to fully simulate the desired relationship.

\section{CONCLUSIONS}

Our results show that the ANN is able to predict the sea water level time series with better accuracy than the numerical MOHID model, over short and long term duration with at least seven days of observations, suggesting that ANNs can be a valuable tool for estuarine management.

To improve the forecasting accuracy of the hydrodynamic model, the ANN could be introduced to mimic the errors introduced by the tide model. This is achieved by training the ANN using the hydrodynamic model output as input, and the results after data assimilation as the targeted output (Mourre et al. 2006). The trained ANN will be used in the future as a post-processor of the output from the hydrodynamic model.

\section{References}

Campuzano, F., J.O. Pierini, and P. Leitão (2008), Hydrodynamics and sediments in Bahía Blanca estuary. Data analysis and modelling. In: R. Neves, J. Baretta, and M. Mateus (eds.), Perspectives on Integrated Coastal Zone Management in South America, IST Scientific Publishers, Lisbon, 483-503.

Chapra, S.C. (1997), Surface Water Quality Modeling, Water Resources and Environmental Engineering Series, McGraw-Hill, New York, 850 pp.

Deo, M.C., and G. Chaudhari (1998), Tide prediction using neural networks, Comput. Aided Civil Infrastruc. Eng. 13, 2, 113-120, DOI: 10.1111/08859507.00091.

Fahlman, S.E. (1988), An empirical study of learning speed in back-propagation networks, Technical report CMU-CS-88-162, Carnegie-Mellon University, Computer Science Dept., Pittsburgh, USA.

Grubert, J. (1995), Prediction of estuarine instabilities with artificial neural networks, J. Comput. Civil Eng. ASCE 9, 4, 266-274, DOI: 10.1061/ (ASCE)0887-3801(1995)9:4(266).

Huang, W., C. Murray, N. Kraus, and J. Rosati (2003), Development of a regional neural network for coastal water level predictions, Ocean Eng. 30, 17, 2275-2295, DOI: 10.1016/S0029-8018(03)00083-0.

IOC, IHO, BODC (2003), Centenary edition of the GEBCO digital atlas, Intergovernmental Oceanographic Commission and the International Hydrographic 
Organization as part of the General Bathymetric Chart of the Oceans; British Oceanographic Data Centre, Liverpool (CD-ROM).

Jacobs, R.A. (1988), Increased rates of convergence through learning rate adaptation, Neural Network 1, 4, 295-307, DOI: 10.1016/0893-6080(88) 90003-2.

Lee, T.-L. (2004), Back-propagation neural network for long-term tidal predictions, Ocean Eng. 31, 2, 225-238, DOI: 10.1016/S0029-8018(03)00115-X.

Leitão, P.C. (2003), Integration of scales and processes in the marine environment modelling, Ph.D. Thesis, Technical Superior Institute, Lisbon.

Lovallo, M., J.O. Pierini, and L. Telesca (2012), Power spectrum and FisherShannon information plane analysis of tidal records, Physica $A$ 391, 20, 4711-4719, DOI: 10.1016/j.physa.2012.05.047.

Makarynskyy, O. (2004), Improving wave predictions with artificial neural networks, Ocean Eng. 31, 5-6, 709-724, DOI: 10.1016/j.oceaneng.2003. 05.003 .

Martins, F., P.C. Leitão, A. Silva, and R. Neves (2001), 3D modelling in the Sado estuary using a new generic vertical discretization approach, Oceanol. Acta 24, Suppl. 1, 51-62, DOI: 10.1016/S0399-1784(01)00092-5.

Mase, H. (1995), Evaluation of artificial armour layer stability by neural network method. In: Proc. 26th Congress of IAHR, London, Int. Assoc. Hydraul. Res., The Netherlands, 341-346.

Mase, H., M. Sakamoto, and T. Sakai (1995), Neural network for stability analysis of rubble-mound breakwaters, J. Waterw. Port Coast. Ocean Eng. ASCE 121, 6, 294-299, DOI: 10.1061/(ASCE)0733-950X(1995)121:6(294).

Mourre, B., L. Crosnier, and C. Le Provost (2006), Real-time sea-level gauge observations and operational oceanography, Philos. Trans. Roy. Soc. A 364, 1841, 867-884, DOI: 10.1098/rsta.2006.1743.

Pierini, J.O. (2007), Circulación y transporte en zonas costeras del estuario de Bahía Blanca, Ph.D. Thesis, Universidad de Buenos Aires, Buenos Aires, 225 pp. (in Spanish).

Pierini, J.O., and E. Gómez (2009), Tidal forecasting using RNN in Bahia Blanca estuary, Argentina, Interciencia 34, 12, 851-856.

Pierini, J.O., J.E. Marcovecchio, F. Campuzano, and G.M.E. Perillo (2008a), Evolution of salinity and temperature in Bahía Blanca estuary, Argentina. In: R. Neves, J.W. Baretta, and M. Mateus (eds.), Perspectives on Integrated Coastal Zone Management in South America, IST Scientific Publishers, Lisbon, 505-513.

Pierini, J.O., F. Campuzano, J. Marcovecchio, and G.M.E. Perillo (2008b), The application of MOHID to assess the potential effect of sewage discharge system at Bahía Blanca estuary (Argentina). In: R. Neves, J.W. Baretta, and M. Mateus (eds.), Perspectives on Integrated Coastal Zone Management in South America, IST Scientific Publishers, Lisbon, 515-522. 
Pierini, J.O., J. Marcovecchio, F. Campuzano, and G.M.E. Perilo (2008c), MOHID oil spill modelling in coastal zones: A case study in Bahía Blanca estuary (Argentina). In: R. Neves, J.W. Baretta, and M. Mateus (eds.), Perspectives on Integrated Coastal Zone Management in South America, IST Scientific Publishers, Lisbon, IST Scientific Publishers, 523-528.

Pierini, J.O., M.E. Streitenberger, and M.D. Baldini (2012), Evaluation of faecal contamination in Bahía Blanca estuary (Argentina) using a numerical model, Rev. Biol. Mar. Oceanogr. 47, 2, 193-202.

Rumelhart, D.E., G.E. Hinton, and R.J. Williams (1986), Learning representations by back-propagating errors, Nature 323, 6088, 533-536, DOI: 10.1038/ $323533 \mathrm{a} 0$.

Tsai, C.-P., and T.-L. Lee (1999), Back-propagation neural network in tidal-level forecasting, J. Waterw. Port Coast. Ocean Eng. ASCE 125, 4, 195-202, DOI: 10.1061/(ASCE)0733-950X(1999)125:4(195).

Vaziri, M. (1997), Predicting Caspian Sea surface water level by ANN and ARIMA models, J. Waterw. Port Coast. Ocean Eng. ASCE 123, 4, 158-162, DOI: 10.1061/(ASCE)0733-950X(1997)123:4(158).

Williams, T.P. (1994), Predicting changes in construction cost indexes using neural networks, J. Constr. Eng. Mgmt. ASCE 120, 2, 306-320, DOI: 10.1061/ (ASCE)0733-9364(1994)120:2(306).

Willmott, C.J. (1982), Some comments on the evaluation of model performance, Bull. Am. Meteorol. Soc. 63, 11, 1309-1369, DOI: 10.1175/1520-0477 (1982)063<1309:SCOTEO>2.0.CO;2. 